\title{
DESIGN PROCESS OF TECHNOLOGICAL LINE FOR VEGETABLES PACKAGING USING CAX TOOLS
}

\author{
Andrzej Lukaszewicz ${ }^{1}$, Kamil Panas ${ }^{2}$, Ryszard Szczebiot ${ }^{3}$ \\ ${ }^{1}$ Bialystok University of Technology, Poland; ${ }^{2}$ PROMOTECH, Poland; ${ }^{3}$ Lomza State University of \\ Applied Sciences, Poland \\ a.lukaszewicz@pb.edu.pl,kamil1324@gmail.com,rysbiot@pwsip.edu.pl
}

\begin{abstract}
The article presents the process of designing a technological line for transporting and packaging vegetables using a parametric $3 \mathrm{D}$ CAD system. On the basis of calculations, individual components of the device were modelled. 3D models of standard components from 3D parts libraries and manufacturer's portals were also used. The designed stand, intended for mounting on a mobile platform for harvesting vegetables, is characterized by a simple construction. It consists of a conveyor for transport of vegetables and a framework that makes it easier for employees to pack products. In this project, ergonomic aspects were also taken into account. As a result of the activities based on the design process carried out with the use of CAx tools, a comprehensive stand for packaging vegetables has been proposed.
\end{abstract}

Keywords: CAx, technological line, vegetables packaging, food packaging.

\section{Introduction}

Innovative food packaging solutions are a current scientific problem [1]. Active packaging techniques [2-3] are still rapidly developing for the aim of longer freshness of food [4-5] and to decrease the amount of waste [6].

Packaging design plays many roles in the product development. This should be creative and innovative to compete with other producers of food. The use of optimization tools [7] and CAx techniques [8] makes it more competitive. Quality function development (QFD) method applied into Computer Aided Design (CAD) systems [9] and some semantic approaches [10] allow for Small \& Medium Enterprises (SME's) improve the effectiveness in market.

CAx tools are also used in design of technological lines in the food branch. The technological line, as one of the ways of organizing the production process, is a set of workstations, in which various activities are related to the production of the product.

During the design process of the device, the appropriate planning of the mechanical structure is an essential factor. CAx (CAD/CAM/CAE) systems are widely used in mechanical engineering [11-13]. The main advantage of design using systems CAx is a shortening of the time development of the project. The correct execution of the 3D model also allows for easy introduction of the necessary changes. The ability to perform structural analysis, visualization and technical documentation in the design phase allows you to better fit the assumptions.

This project is a response to the need to organize the processes of transport and packaging to be carried out on a mobile platform to harvest vegetables. For this reason, one of the design intents was the specified workspace. The following operations will be performed:

- transport to the packing station with the conveyor,

- qualitative selection of vegetables,

- packing in cartons by employees.

For this reason, the design of the station is a combination of two main components - a conveyor, which enables automatic transport of celery on the platform and a structure responsible for facilitating the packaging of vegetables for cartons by employees. The project of the position has to take into account many factors, including working environment, safety and ergonomics, and easy assembly on the machine. During the design work, operational and constructional assumptions were defined, which governs the selection of individual components of the unit. Operational assumptions are:

- safety on unit,

- ergonomics,

- easy use and repair,

- support by 5 employees for packaging vegetables and 2 people for palleting,

- easy to keep clean. 
Design assumptions are:

- $\quad$ performance conveyor $60-150 \mathrm{pcs} \cdot \mathrm{min}^{-1}$,

- workspace $2.5 \mathrm{~m} \mathrm{x} 7 \mathrm{~m}$,

- modularity and mobility positions,

- simple design and easy installation on the machine,

- use of materials appropriate for the food industry,

- application of the electric drive conveyor with adjustable speed.

One of the main construction assumptions of the station is the conveyor efficiency, meaning the amount of material that will be transported in a given unit of time. This limit results from the pace of work of employees responsible for packaging vegetables. This assumption requires proper selection of the conveyor drive - an electric motor with the appropriate ratio, and ensuring the possibility of controlling the device. The construction of the post must be adapted to the dimensions, postures and movements of the human in such a way that it does not cause him difficulties during work. The location of the station has a significant impact on the ergonomics of working on the machine. The construction should not take up much space due to its limited number on the platform. Comfort and freedom of movement of employees translate into better work efficiency.

\section{Materials and methods}

Before the final 3D model of the device, it is essential to have the proper layout of its structure that meets all of the assumptions. To this end, the initial position of the scheme is made, presented in Fig. 1.

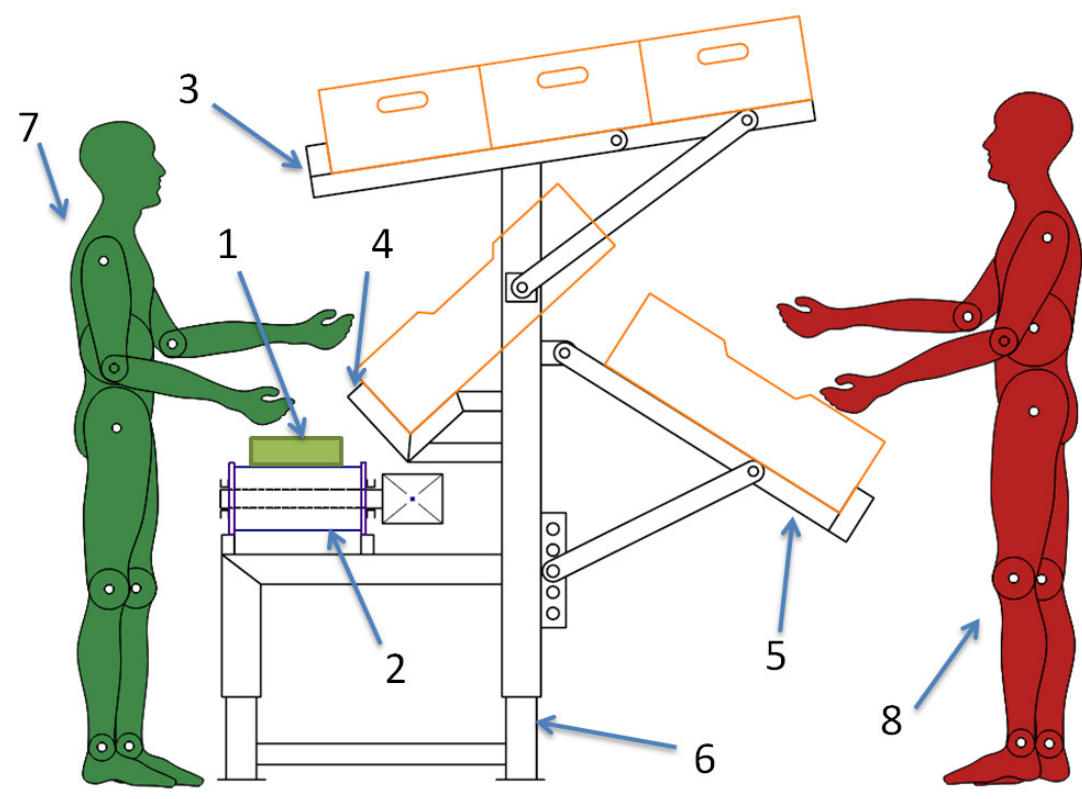

Fig. 1. Proposed scheme: 1 - product packed; 2 - vegetable conveyor; 3 - toolbox empty cardboard boxes; 4 - device for easy packing; 5 - adjustable supporting arm full of cardboard boxes; 6 - position

height adjustable; 7 - employee packing vegetables; 8 - employee responsible for compilation of cartons on the pallet

There are many types of elevators or conveyors used in agriculture [e.g., 14], therefore, the right choice of the mode of transport is very important, both from the point of view of the correctness of the design of the device, and later the lifecycle. An important part is the position to the conveyor, i.e. a handling device, intended to move loose materials or specific charges, after a certain track [15-16]. A significant impact on the right choice of the conveyor has a number of factors, such as:

- type and properties of the transported material,

- local conditions,

- ability to properly shape the conveyor operation,

- cost of acquisition and exploitation. 
The structural design was best matched by a modular conveyor. It belongs to the group of wire conveyors. The material is moved using the members connected to each other in a closed circuit. They are perfect for transporting unit loads on a curved track and are easy to keep clean, which perfectly suits the conditions on the platform of the combine harvester. An exemplary module conveyor is shown in Fig. 2.

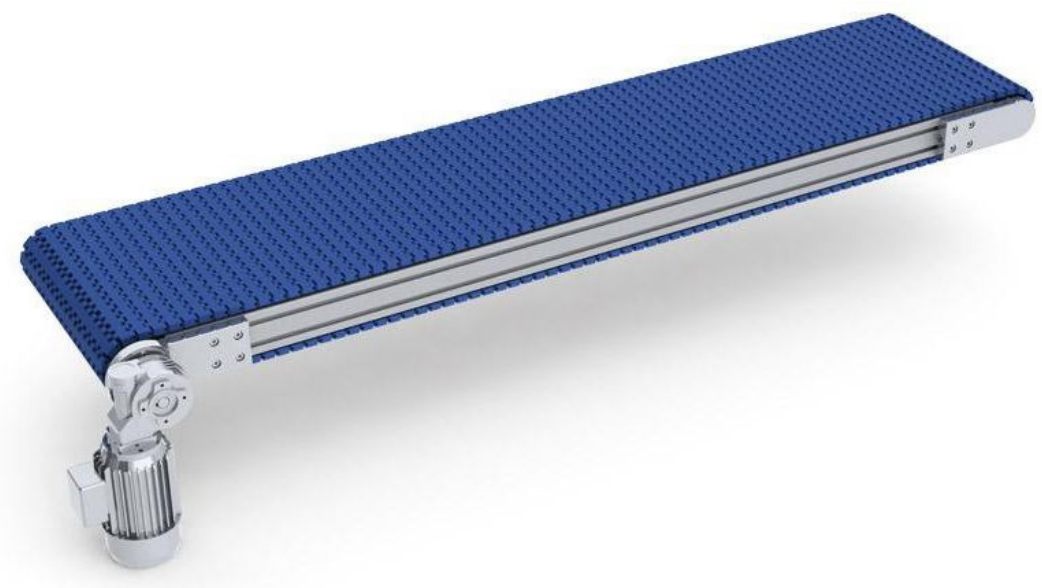

Fig. 2. Example of modular conveyor [17]

Advantages of modular belts [17]:

- possibility of transporting products in a curve,

- good mechanical properties - belt components are made of plastic, weather-resistant and good sliding properties,

- easy to clean the line,

- possibility of using additional equipment, including drivers, side stops,

- possibility of easy replacement of damaged modules,

- it is possible to create tapes of different width and length.

The drive of the designed conveyor is an electric gear motor with the appropriate power and transmission ratio. It is located at one end of the conveyor. At the other end, there is a plastic roll that acts as a reversible tape. The movement of the conveyor belt is caused by the drive shaft through three plastic gear wheels meshing with the belt modules. The number of gears was calculated on the basis of catalog data. The central gear is mounted on the shaft via a clamping ring that removes the possibility of movement along the shaft. The remaining gears adjust their position by engaging the recesses of the belt. In addition, the belt movement from side to side is limited by the conveyor housing covers used. This system is shown in Fig. 3.

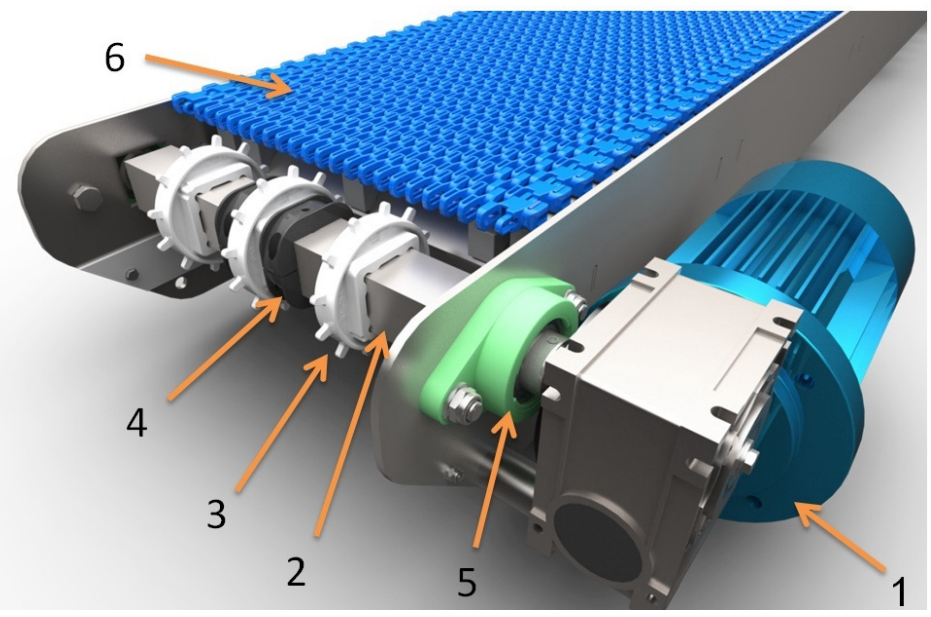

Fig. 3. Drive system of conveyor: 1 - electric gear motor; 2 - drive shaft; 3 - gear; 4 - clamping ring; 5 - bearing; 6 - belt on guideways 
Requirements for designers force them to analyse in detail methods of project implementation and to choose the best design method [11]. The design process required the creation of a correct and editable 3D model of the position. The parametric SolidWorks software was used as the main tool supporting the process of developing the position for transporting and packaging vegetables. Using different modelling techniques, for example multibody techniques [18], one had to proceed in such a way that the implementation of unavoidable modifications requires minimum commitment. The design of the technological line, being the subject of the work, required the development of a preliminary concept, taking into account all the design and operational assumptions. Calculations and analysis were used to choose the parts of the directory including an electric gear motor, bearings and modular belt components. The final model of the station is composed of many parts and subassemblies as the effect of linking many geometric elements. This requires more data that must be loaded and recalculated during operation, which leads to increased use of computer memory resources. For this reason, it is extremely important to properly plan the assembly structure, which can be presented in the form of a block diagram (Fig. 4). The design of the stand was divided into many sub-assemblies. The main subassemblies are the vegetable conveyor and the rack for packaging. After creating the base weldments of the rack frame, further components were gradually added. When creating the conveyor casing, sheet metal tools were used.

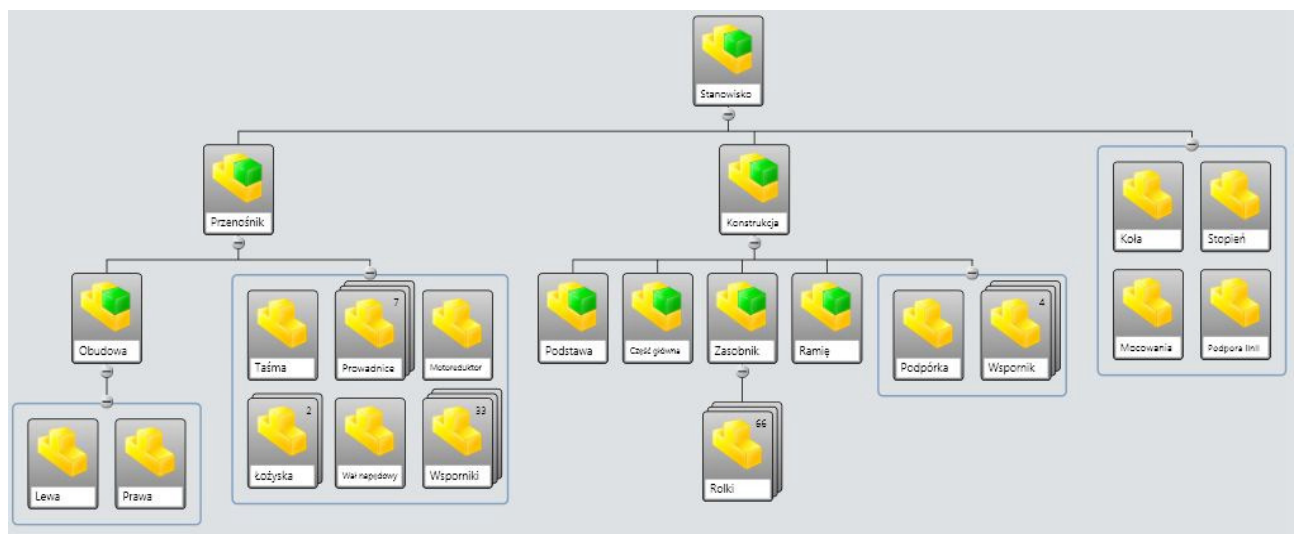

Fig. 4. Division of assembly structure of proposed technological line

\section{Results and discussion}

The final model takes into account the ergonomic aspects of work in the workplace [19]. The frame base is adjustable in height (the frame can be raised by $230 \mathrm{~mm}$ ) and its position can be fixed with screws. Employees also have the option of adjusting the arm supporting the full cartons. Downloading of cartons from the tray and moving them to the other side is facilitated by rotating rollers. In order to check the ergonomics of the designed structure, imported human body models were used (Fig. 5). The reverse engineering techniques [20] can be used to accurately reproduce the natural shapes of vegetables and use them in the 3D CAD model of workspace.

Libraries integrated with CAD software enable the use of existing or pre-prepared parts, operations or diagrams. This allows you to shorten the time needed to complete a given 3D model. Frequently used commercial parts, eg., screws, nuts, bearings, do not require re-modelling, but only selections from the ready list and insertion into the project. In addition to existing collections offered by different manufacturers, it is also possible to create your own library containing prepared elements. A valid and functional project library helps reduce the amount of time and work performed, and allows quick and easy access to the created part and assembly files.

The completed model of the position required creating a library of profiles based on the manufacturer's catalog. To do this, after creating your own profile sketch and saving it as a SolidWorks library file, you have specified "custom properties". Thanks to them, during the preparation of the 2D drawings, the dimensions of the profile are automatically displayed on the bill of materials and the list of cut elements. The defined profiles were used in the design process of welded structures. Another activity performed during the creation of the project library was the import of selected manufacturer's parts catalog, stored in neutral CAD export-import formats (e.g., IGS, STEP), including the gearmotor, bearings and modular tape components. 


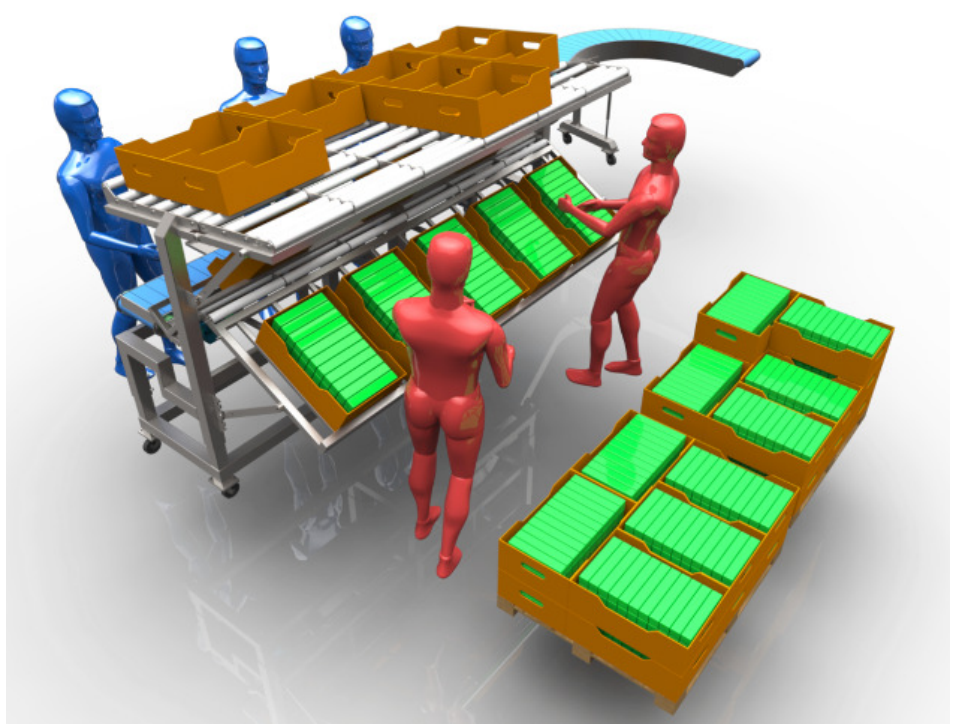

Fig. 5. Visualization of workplace with 3D models of employees

The PhotoView module available with the SolidWorks software was used to visualize the design of the stand for transporting and packing vegetables. The parts were given material; the right stage and lighting were selected. The visualization of the created model of the station is shown in Fig. 6.

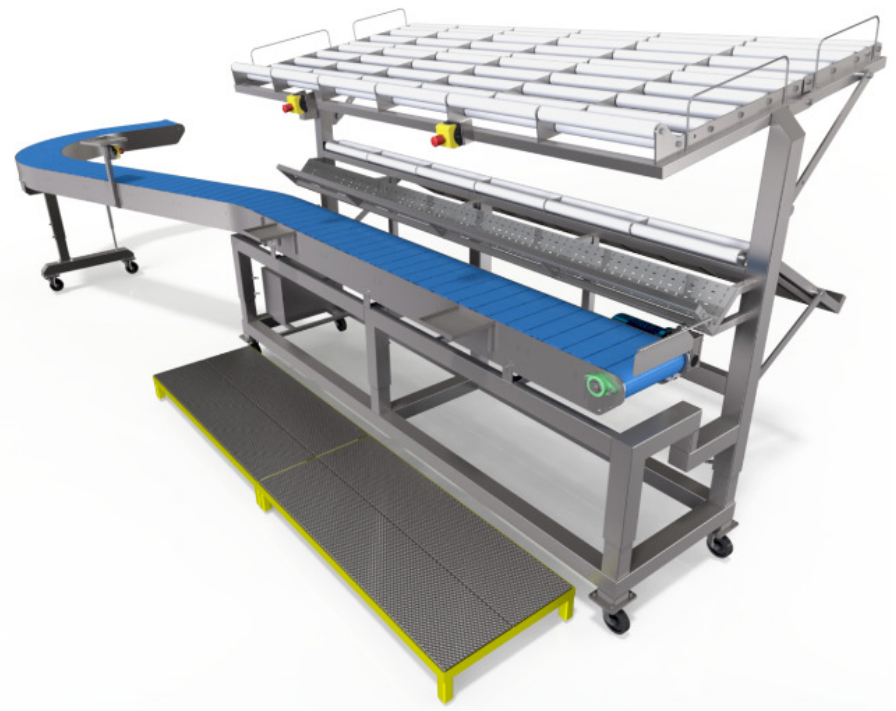

Fig. 6. Visualization of 3D model

\section{Conclusions}

The development of the project of the technological line was required completion of many design purposes and subject to the rules of ergonomics. The development process was greatly simplified by the use of CAx possibilities. SolidWorks was the environment of CAx tools. Using different modelling methods preliminary concept of the technological line to vegetabl packaging was converted into a 3D model using its own library bases. The main advantage of design by using CAx systems is a significant reduction in the development time of the project. The correct execution of 3D models also makes it easy to introduce the necessary changes in the design. The ability to perform structural analysis, visualization, and 2D drawings in the design phase allows to better adapt the device to the assumptions of the design.

\section{Acknowledgements}

This paper was performed within a framework of S/WM/1/2018 realised in Bialystok University of Technology and financed with funds from the Ministry of Science and Higher Education. 


\section{References}

[1] Brody A.L., Bugusu B., Han J.H., Sand C.K., McHugh T.H. Innovative food packaging solutions. Journal of food science, vol. 73, issue 8, 2008, pp. 107-116.

[2] Pereira de Abreu D.A., Cruz J.M., Paseiro Losada P. Active and intelligent packaging for the food industry. Food Reviews International, vol. 28, issue 10, 2012, pp. 146-187.

[3] Wyrwa J., Barska A. Innovations in the food packaging market: active packaging. European Food Research and Technology, vol. 234, issue 10, 2013, pp. 1681-1692.

[4] Castro-Ibáñez I., Gil M.I., Allende A. Ready-to-eat vegetables: Current problems and potential solutions to reduce microbial risk in the production chain. LWT-food science and technology, vol. 85, part B, 2017, pp. 284-292.

[5] Yousuf B., Qadri O.S., Srivastava A.K. Recent developments in shelf-life extension of fresh-cut fruits and vegetables by application of different edible coatings: A review. LWT-food science and technology, vol. 89, 2018, pp. 198-209.

[6] Poyatos-Racionero E., Ros-Lis J.V., Vivancos J.-L., Martínez-Máñez R. Recent advances on intelligent packaging as tools to reduce food waste. Journal of Cleaner Production, vol. 172, 2018, pp. 3398-3409.

[7] Francese M.A., Francese D.L. Food packaging optimization by means of integrated CAD/CAE and statistical techniques. Proceedings of 4th International Conference on Simulation and Modelling in the Food and Bio Industry (FOODSIM 2006), June 15-17, 2006, Naples, Italy, pp. $85-90$

[8] Miatliuk K., Łukaszewicz A., Siemieniako F. Coordination method in design of forming operations of hierarchical solid objects. Proceedings of International Conference on Control, Automation and Systems: ICCAS'2008, October 14-17, 2008, Seoul, South Korea, pp. 2724-2357.

[9] Marjudi S., Sulaiman R., Majid N.A.A., Amran M.F.M., Rauf M.F.A., Kahar S. QFD in Malaysian SMEs food packaging CAD (PackCAD) testing. Procedia Technology, 2013, pp. 518-524.

[10] Abidin S.Z., Effendi R.A.A.R.A., Ibrahim R., Idris M.Z. A semantic approach in perception for packaging in the SME's food industries in Malaysia: a case study of Malaysia food product branding in United Kingdom. Procedia - Social and Behavioral Sciences, vol. 115, 2014, pp. 115-130.

[11] Wełyczko A. CATIA V5. Przykłady efektywnego zastosowania systemu w projektowaniu mechanicznym (CATIA V5. Examples of effective system application in mechanical design). Gliwice, Helion, 2005. 352 p. (In Polish).

[12] Puodziuniene N. Review of Contemporary CAD Systems in Industry and Education. Proceedings of 17th International Conference on Mechanika. April 12-13, 2012, Kaunas Univ. Technol., Kaunas, Lithuania, pp. 246-250.

[13] Łukaszewicz A., Skorulski G., Szczebiot R. Main aspects of training in the field of computeraided techniques (CAx) in mechanical engineering. Proceedings of 17th International Scientific Conference on Engineering for Rural Development, May 23-25, 2018, Jelgava, Latvia, pp. 865-870.

[14] Huscio T., Trochimczuk R. Novel rope-free mechatronic elevator system to automation of transport in agricultural farms. Proceedings of 15th International Scientific Conference on Engineering for Rural Development, May 25-27, 2016, Jelgava, Latvia, pp. 318-323.

[15] Goździecki M., Świątkiewicz H. Przenośniki (Conveyors). Warszawa, Wydawnictwa NaukowoTechniczne, 1979. 362 p.(In Polish).

[16] Fayed M.E., Skocir T. Mechanical Conveyors: Selection and Operation. CRC Press, 1996. 485 p.

[17] Haberkorn. [online][19.05.2018] Available at: http://www.haberkorn.pl/przenosniki-modularne/

[18] Łukaszewicz A. Modelling of solid part using multibody techniques in parametric CAD systems. Solid State Phenomena, vols. 147-149, 2009, pp. 924-929.

[19] Kawecka-Endler A., Mrugalska B. Praktyczne aspekty projektowania ergonomicznego w budowie maszyn (Practical aspects of ergonomic design in mechanical engineering). Poznań Wydawnictwo Politechniki Poznańskiej, 2011.90 p. (In Polish).

[20] Łukaszewicz A., Miatluk K. Reverse Engineering Approach for Object with Free-Form Surfaces Using Standard Surface-Solid Parametric CAD System. Solid State Phenomena, vols. 147-149, pp. 706-711. 